\title{
Polycyclic aromatic hydrocarbons at fire stations: firefighters' exposure monitoring and biomonitoring, and assessment of the contribution to total internal dose
}

\author{
Marta Oliveira a,b, Klara Slezakova ${ }^{\mathrm{a}, \mathrm{b}}$, Maria José Alves ${ }^{\mathrm{c}}$, Adília Fernandes ${ }^{\mathrm{c}}$, \\ João Paulo Teixeira ${ }^{\mathrm{d}, \mathrm{e}}$, Cristina Delerue-Matos $^{\mathrm{a}}$, Maria do Carmo Pereira ${ }^{\mathrm{b}}$, \\ Simone Morais ${ }^{\mathrm{a}, *}$ \\ a REQUIMTE-LAQV, Instituto Superior de Engenharia, Instituto Politécnico do Porto, R. Dr. António Bernardino de Almeida 431, 4200-072 Porto, Portugal \\ ${ }^{\mathrm{b}}$ LEPABE, Departamento de Engenharia Química, Faculdade de Engenharia, Universidade do Porto, R. Dr. Roberto Frias, $4200-465$ Porto, Portugal \\ c Escola Superior de Saúde, Instituto Politécnico de Bragança, Avenida D. Afonso V, 5300-121, Bragança, Portugal \\ d Instituto Nacional de Saúde Pública, Departamento de Saúde Ambiental, Rua Alexandre Herculano 321, 4000-055 Porto, Portugal \\ e Universidade do Porto, Instituto de Saúde Pública, Rua das Taipas 135, 4050-600 Porto, Portugal
}

\section{H I G H L I G H T S}

- Firefighters exposure to PAHs was assessed by personal monitoring and biomonitoring.

- Airborne PAHs with 2-3 rings were the most abundant at all fire stations.

- 1-hydroxynaphthalene and 1-hydroxyacenaphthene were the predominant metabolites.

- Naphthalene contributed the most to carcinogenic PAHs in majority of firehouses.

- Significant correlations were found among urinary OH-PAH excretion and inhaled PAHs.

\section{A R T I C L E I N F O}

\section{Article history:}

Received 30 December 2015

Received in revised form 1 March 2016

Accepted 5 March 2016

Available online 8 March 2016

\section{Keywords:}

Firefighters

Exposure

Polycyclic aromatic hydrocarbons (PAHs)

Monohydroxyl-PAHs (OH-PAHs)

1-hydroxypyrene

\begin{abstract}
A B S T R A C T
This work characterizes levels of eighteen polycyclic aromatic hydrocarbons (PAHs) in the breathing air zone of firefighters during their regular work shift at eight Portuguese fire stations, and the firefighters' total internal dose by six urinary monohydroxyl metabolites (OH-PAHs). Total PAHs ( $\Sigma$ PAHs) concentrations varied widely (46.4-428 ng/ $\mathrm{m}^{3}$ ), mainly due to site specificity (urban/rural) and characteristics (age and layout) of buildings. Airborne PAHs with 2-3 rings were the most abundant (63.9-95.7\% $\Sigma$ PAHs). Similarly, urinary 1-hydroxynaphthalene and 1-hydroxyacenaphthene were the predominant metabolites (66-96\% $\Sigma$ OH-PAHs). Naphthalene contributed the most to carcinogenic $\Sigma$ PAHs (39.4-78.1\%) in majority of firehouses; benzo[a]pyrene, the marker of carcinogenic PAHs, accounted with $1.5-10 \%$. Statistically positive significant correlations $(r \geq 0.733, p \leq 0.025)$ were observed between $\Sigma$ PAHs and urinary $\Sigma \mathrm{OH}-\mathrm{PAHs}$ for firefighters of four fire stations suggesting that, at these sites, indoor air was their major exposure source of PAHs. Firefighter's personal exposure to PAHs at Portuguese fire stations were well below the existent occupational exposure limits. Also, the quantified concentrations of post-shift urinary 1-hydroxypyrene in all firefighters were clearly lower than the benchmark level $(0.5 \mu \mathrm{mol} / \mathrm{mol})$ recommended by the American Conference of Governmental Industrial Hygienists.
\end{abstract}

(C) 2016 Elsevier B.V. All rights reserved.

\section{Introduction}

Firefighting, along with construction, mining, and agriculture, ranks among the most dangerous professions, with its occupational exposure being regarded as possible carcinogen to humans

\footnotetext{
* Corresponding author.

E-mail address: sbm@isep.ipp.pt (S. Morais).
}

by the International Agency for Research on Cancer (IARC) and the US National Institute for Occupational Safety and Health (NIOSH) $[1,2]$. Firefighting is among the most hazardous yet the least studied occupations in terms of exposures and their relationship to occupational diseases.

Polycyclic aromatic hydrocarbons (PAHs) are ubiquitous compounds that are released during the incomplete combustion or pyrolysis of organic material. PAHs are well known for their cytotoxic and mutagenic properties [3,4], with some 
of them being recognized as endocrine disrupting chemicals [5]; USEPA listed 16 priority PAHs [6]. PAHs possess an undeniable role in the induction of human carcinogenesis [7], especially if benzo[a]pyrene (known human carcinogenic) and benz[a]anthracene, benzo[b]fluoranthene, benzo[j]fluoranthene, benzo[k]fluoranthene, chrysene, indeno[1,2,3-cd]pyrene, and naphthalene (possible human carcinogens; [4,8] are present. Dibenzo[a,l]pyrene and dibenz[a,h]anthracene have been also under scrutiny because they are regarded as probable carcinogens to humans due to their higher carcinogenic potency than benzo[a]pyrene [9-12]. Electrophilic compounds such as PAHs play a key role in environmental cancer and some recent evidences associate their role in cardiovascular disease [13]. Firefighters' occupational exposure has been associated with excess morbidity and mortality with cardiovascular disease being considered as the leading cause of death in approximately $45 \%$ of firefighters and a major cause of their morbidity [14-16]. As a consequence firefighters' occupational exposure to PAHs may promote the development or aggravation of cardiovascular illnesses. Fires are the major contributor to occupational exposure to PAHs [17-20]. Other relevant sources include motor-vehicle exhaust (especially diesel), industrial emissions, residential and commercial heating with wood, coal, or other biomass fuels, and tobacco smoke [21-23]. Despite some available information regarding firefighters' occupational exposure to PAHs during live fire combat activities in Australia [20] and USA [17-19,23-27], firefighters may also be exposed to PAHs when they are at fire stations. Recently some studies revealed that chemical contaminants from fires were tracked back to fire stations via fire vehicles and principally through firefighters' personal equipments such as boots, gloves, and turnout gear [18,20,28-31]. Only two studies were found regarding firefighters' occupational exposure to PAHs at fire stations [23,32], both performed in USA. No information exists concerning other countries, even though the available exposure data may not be directly applicable.

Biological monitoring is an important tool in the prevention of occupational diseases related to those exposed chemicals on a regular basis, particularly when multi-route exposure (inhalation, dermal, ingestion) or abnormal exposure takes place. 1-hydroxypyrene (10HPy) is the most widely used biological indicator of internal dose of PAHs exposure [33,34]; 3-hydroxibenzo[a]pyrene (3OHBaP) is the main metabolite of the known human carcinogenic benzo[a]pyrene. Acenaphthene, fluorene, and phenanthrene are common PAHs in different matrices $[10,35,36]$ and their major urinary metabolites are 1-hydroxylacenaphthene (10HAce), 2-hydroxylfluorene (2OHFlu), and 1-hydroxyphenanthrene (10HPhen), respectively. Regarding naphthalene there are more than thirty

Table 1

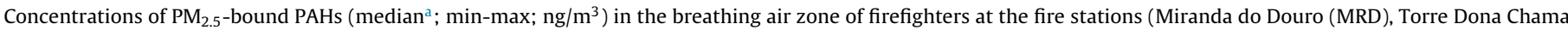
(TDC), Sendim (SDM), Mirandela (MDL), Torre de Moncorvo (TMC), Vinhais (VNH), Bragança (BRG), and Freixo de Espada à Cinta (FEC)).

\begin{tabular}{|c|c|c|c|c|c|c|c|c|}
\hline \multirow[t]{2}{*}{ Compound } & \multicolumn{8}{|l|}{ Fire station } \\
\hline & MRD & TDC & SDM & MDL & TMC & $\mathrm{VNH}$ & BRG & FEC \\
\hline Naphthalene & $\begin{array}{l}12.2 \\
(8.51-15.1)\end{array}$ & $\begin{array}{l}6.67 \\
(5.61-6.99)\end{array}$ & $\begin{array}{l}7.95 \\
(6.04-10.3)\end{array}$ & $\begin{array}{l}11.5 \\
(10.9-13.5)\end{array}$ & $\begin{array}{l}4.95 \\
(4.27-8.74)\end{array}$ & $\begin{array}{l}7.19 \\
(5.95-8.53)\end{array}$ & $\begin{array}{l}9.21 \\
(4.23-13.0)\end{array}$ & $\begin{array}{l}35.5 \\
(33.4-38.6)\end{array}$ \\
\hline Acenaphthylene & $\begin{array}{l}110 \\
(75.6-208)\end{array}$ & $24.0^{\mathrm{a}}$ & $\begin{array}{l}56.4 \\
(27.8-86.9)\end{array}$ & $\begin{array}{l}125^{* *} \\
(24.0-198)\end{array}$ & $24.0^{\mathrm{a}}$ & $\begin{array}{c}43.9^{* * *} \\
(24.0-89.1)\end{array}$ & $\begin{array}{c}27.2^{* * *} \\
(24.0-111)\end{array}$ & $\begin{array}{l}199 \\
(60.3-352)\end{array}$ \\
\hline Acenaphthene & $\begin{array}{l}88.5 \\
(56.1-111)\end{array}$ & $\begin{array}{l}2.48^{* *} \\
(1.62-4.26)\end{array}$ & $\begin{array}{l}18.7 \\
(18.4-20.8)\end{array}$ & $\begin{array}{l}97.3^{* *} \\
(1.62-121)\end{array}$ & $\begin{array}{l}10.3 \\
(9.11-16.2)\end{array}$ & $1.62^{\mathrm{a}}$ & $\begin{array}{l}8.54^{* * *} \\
(1.62-18.2)\end{array}$ & $\begin{array}{l}4.33^{* * *} \\
(1.62-8.02)\end{array}$ \\
\hline Fluorene & $\begin{array}{l}1.05 \\
(0.540-1.49)\end{array}$ & $\begin{array}{l}0.272^{* * *} \\
(0.272-0.588)\end{array}$ & $0.272^{\mathrm{a}}$ & $\begin{array}{l}1.86 \\
(1.62-3.53)\end{array}$ & $\begin{array}{l}0.446^{* *} \\
(0.272-0.528)\end{array}$ & $0.272^{\mathrm{a}}$ & $\begin{array}{l}0.272^{* * *} \\
(0.272-0.450)\end{array}$ & $\begin{array}{l}6.73 \\
(3.13-9.94)\end{array}$ \\
\hline Phenanthrene & $\begin{array}{l}6.07 \\
(3.74-7.27)\end{array}$ & $\begin{array}{l}4.08 \\
(3.71-5.97)\end{array}$ & $\begin{array}{l}2.88 \\
(2.76-3.00)\end{array}$ & $\begin{array}{l}9.45 \\
(6.83-9.88)\end{array}$ & $\begin{array}{l}3.99 \\
(3.39-4.42)\end{array}$ & $\begin{array}{l}4.32 \\
(3.42-5.01)\end{array}$ & $\begin{array}{l}3.63 \\
(2.97-4.84)\end{array}$ & $\begin{array}{l}28.5 \\
(21.0-35.9)\end{array}$ \\
\hline Anthracene & $0.223^{\mathrm{a}}$ & $\begin{array}{l}0.223^{* * * *} \\
(0.223-0.364)\end{array}$ & $0.223^{\mathrm{a}}$ & $\begin{array}{l}0.223^{* * *} \\
(0.223-1.59)\end{array}$ & $0.223^{\mathrm{a}}$ & $\begin{array}{l}0.223^{* * *} \\
(0.223-0.657)\end{array}$ & $0.223^{\mathrm{a}}$ & $\begin{array}{l}0.636 \\
(0.601-0.675)\end{array}$ \\
\hline Fluoranthene & $\begin{array}{l}0.351^{* * *} \\
(0.351-0.603)\end{array}$ & $\begin{array}{l}0.351^{* * *} \\
(0.351-0.592)\end{array}$ & $0.351^{\mathrm{a}}$ & $\begin{array}{l}1.50 \\
(0.968-2.16)\end{array}$ & $\begin{array}{l}0.351^{* * *} \\
(0.351-0.589)\end{array}$ & $\begin{array}{l}0.596^{* *} \\
(0.351-1.02)\end{array}$ & $\begin{array}{l}0.351^{* * *} \\
(0.351-0.631)\end{array}$ & $\begin{array}{l}1.88^{* * *} \\
(0.351-3.88)\end{array}$ \\
\hline Pyrene & $\begin{array}{l}1.24^{* *} \\
(0.292-1.34)\end{array}$ & $0.292^{\mathrm{a}}$ & $0.292^{\mathrm{a}}$ & $\begin{array}{l}2.28 \\
(1.76-2.77)\end{array}$ & $\begin{array}{l}0.473^{* *} \\
(0.292-0.755)\end{array}$ & $\begin{array}{l}0.582^{* *} \\
(0.292-1.09)\end{array}$ & $0.292^{\mathrm{a}}$ & $\begin{array}{l}3.41 \\
(2.01-4.92)\end{array}$ \\
\hline Benz[a]anthracene & $0.205^{\mathrm{a}}$ & $0.205^{\mathrm{a}}$ & $0.205^{\mathrm{a}}$ & $\begin{array}{l}0.205^{* * *} \\
(0.205-0.866)\end{array}$ & $0.205^{\mathrm{a}}$ & $\begin{array}{l}0.205^{* * *} \\
(0.205-0.452)\end{array}$ & $\begin{array}{l}0.205^{* * *} \\
(0.205-0.324)\end{array}$ & $\begin{array}{l}0.446^{* * *} \\
(0.205-0.824)\end{array}$ \\
\hline Chrysene & $\begin{array}{l}0.145^{* * *} \\
(0.145-0.358)\end{array}$ & $0.145^{\mathrm{a}}$ & $0.145^{\mathrm{a}}$ & $\begin{array}{l}0.145^{* * *} \\
(0.145-2.01)\end{array}$ & $\begin{array}{l}0.365^{* *} \\
(0.145-0.475)\end{array}$ & $\begin{array}{l}0.196^{* * *} \\
(0.145-0.743)\end{array}$ & $0.145^{\mathrm{a}}$ & $\begin{array}{l}2.41 \\
(2.01-3.08)\end{array}$ \\
\hline Benzo[b $+\mathrm{j}]$ fluoranthene & $0.844^{\mathrm{a}}$ & $0.844^{\mathrm{a}}$ & $0.844^{\mathrm{a}}$ & $\begin{array}{l}0.844^{* * *} \\
(0.844-3.55)\end{array}$ & $0.844^{\mathrm{a}}$ & $\begin{array}{l}2.31^{* *} \\
(0.844-3.51)\end{array}$ & $0.844^{\mathrm{a}}$ & $\begin{array}{l}24.5 \\
(15.5-33.9)\end{array}$ \\
\hline Benzo[k]fluoranthene & $\begin{array}{l}0.238^{* *} \\
(0.134-0.642)\end{array}$ & $0.134^{\mathrm{a}}$ & $0.134^{\mathrm{a}}$ & $\begin{array}{l}0.134^{* * *} \\
(0.134-0.412)\end{array}$ & $0.134^{\mathrm{a}}$ & $\begin{array}{l}0.399^{* *} \\
(0.134-0.594)\end{array}$ & $0.134^{\mathrm{a}}$ & $\begin{array}{l}3.84 \\
(2.50-5.15)\end{array}$ \\
\hline Benzo[a]pyrene & $\begin{array}{l}0.277^{* * *} \\
(0.277-1.02)\end{array}$ & $\begin{array}{l}0.277^{* * *} \\
(0.277-0.398)\end{array}$ & $0.277^{\mathrm{a}}$ & $\begin{array}{l}0.277^{* * *} \\
(0.277-1.24)\end{array}$ & $0.277^{\mathrm{a}}$ & $\begin{array}{l}1.22^{* *} \\
(0.277-2.45)\end{array}$ & $0.277^{\mathrm{a}}$ & $\begin{array}{l}15.1 \\
(9.76-20.5)\end{array}$ \\
\hline Dibenzo[a,l]pyrene & $0.671^{\mathrm{a}}$ & $0.671^{\mathrm{a}}$ & $0.671^{\mathrm{a}}$ & $0.671^{\mathrm{a}}$ & $0.671^{\mathrm{a}}$ & $0.671^{\mathrm{a}}$ & $0.671^{\mathrm{a}}$ & $0.671^{\mathrm{a}}$ \\
\hline Dibenz[a,h]anthracene & $\begin{array}{l}3.97^{* *} \\
(0.499-13.9)\end{array}$ & $\begin{array}{l}0.499^{* * *} \\
(0.499-1.66)\end{array}$ & $0.499^{\mathrm{a}}$ & $\begin{array}{l}0.767^{* *} \\
(0.499-3.63)\end{array}$ & $0.499^{\mathrm{a}}$ & $\begin{array}{l}5.85^{* *} \\
(0.499-9.96)\end{array}$ & $0.499^{\mathrm{a}}$ & $\begin{array}{l}51.1 \\
(38.1-65.5)\end{array}$ \\
\hline Benzo[ghi]perylene & $\begin{array}{l}3.09^{* *} \\
(0.355-4.48)\end{array}$ & $\begin{array}{l}5.08 \\
(2.66-6.78)\end{array}$ & $\begin{array}{l}1.66 \\
(1.44-1.88)\end{array}$ & $\begin{array}{l}3.80 \\
(2.86-11.8)\end{array}$ & $\begin{array}{l}3.17 \\
(1.98-4.00)\end{array}$ & $\begin{array}{l}4.83 \\
(3.06-8.53)\end{array}$ & $\begin{array}{l}2.29 \\
(1.55-4.18)\end{array}$ & $\begin{array}{l}32.9 \\
(27.9-40.8)\end{array}$ \\
\hline $\begin{array}{l}\text { Indeno[1,2,3- } \\
\text { cd]pyrene }\end{array}$ & $\begin{array}{l}0.185^{* * *} \\
(0.185-1.18)\end{array}$ & $0.185^{a}$ & $0.185^{\mathrm{a}}$ & $0.185^{\mathrm{a}}$ & $0.185^{\mathrm{a}}$ & $0.185^{\mathrm{a}}$ & $0.185^{\mathrm{a}}$ & $\begin{array}{l}17.6 \\
(13.9-23.3)\end{array}$ \\
\hline$\Sigma$ PAHs & $\begin{array}{l}229 \\
(200-296)\end{array}$ & $\begin{array}{l}46.4 \\
(44.0-49.4)\end{array}$ & $\begin{array}{l}91.7 \\
(64.5-124)\end{array}$ & $\begin{array}{l}256 \\
(77.6-352)\end{array}$ & $\begin{array}{l}51.1 \\
(48.8-57.5)\end{array}$ & $\begin{array}{l}74.6 \\
(44.4-125)\end{array}$ & $\begin{array}{l}55.0 \\
(49.8-137)\end{array}$ & $\begin{array}{l}428 \\
(250-631)\end{array}$ \\
\hline$\Sigma \mathrm{PAHs}_{\mathrm{carc}}$ & $\begin{array}{l}20.8 \\
(15.8-26.0)\end{array}$ & $\begin{array}{l}9.82 \\
(8.57-11.1)\end{array}$ & $\begin{array}{l}10.9 \\
(9.00-13.3)\end{array}$ & $\begin{array}{l}16.8 \\
(13.9-23.9)\end{array}$ & $\begin{array}{l}8.24 \\
(7.45-11.7)\end{array}$ & $\begin{array}{l}19.6 \\
(9.43-23.6)\end{array}$ & $\begin{array}{l}12.2 \\
(7.19-16.1)\end{array}$ & $\begin{array}{l}150 \\
(122-186)\end{array}$ \\
\hline
\end{tabular}

Note: Detection frequency of each compound was $100 \%$ unless otherwise indicate.

${ }^{*} 80 \% \leq$ detection frequency $<100 \%$.

** $60 \% \leq$ detection frequency $<80 \%$.

*** $15 \% \leq$ detection. frequency $<60 \%$.

a When the concentration was below the LOD, the value of the respective $\operatorname{LOD} / \sqrt{ } 2$ was used [50]. 


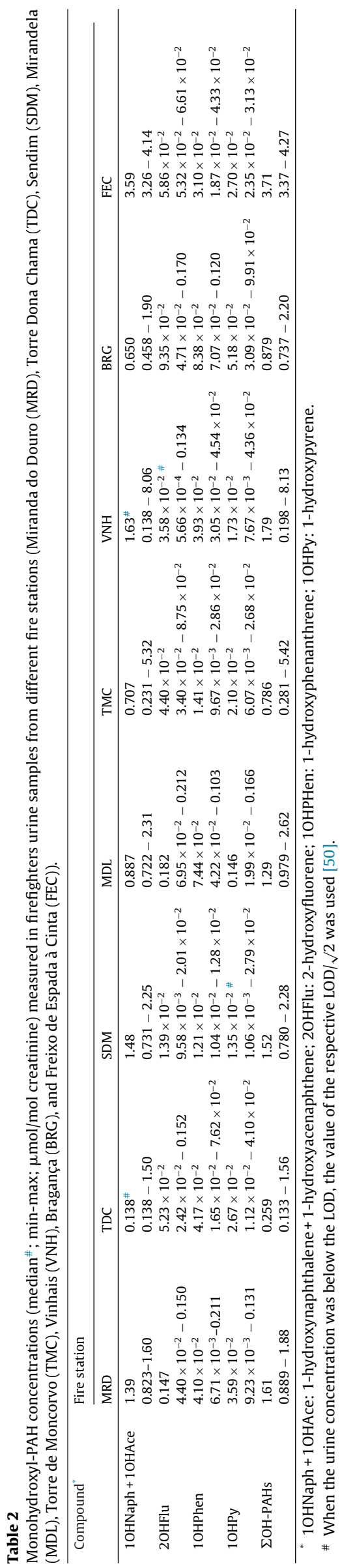

identified metabolites, being 1-hydroxynaphthalene (1OHNaph) and 2-hydroxynaphthalene the main biomarkers of occupational exposure to naphthalene [37]. Only four studies were found in the literature concerning firefighters' biological monitoring to PAHs. Among them, two characterized exclusively 10HPy levels $[27,38]$, while the other two assessed the urinary levels of $10 \mathrm{HPy}$ and 1OHNaph [31], and the concentrations of 1OHPy and three hydroxyphenanthrene metabolites [39], respectively. In order to evaluate firefighters' workplace conditions on a continuous basis, emphasis should be placed on environmental monitoring, complemented by biological monitoring. No study was found about firefighters' occupational exposure to PAHs that simultaneously assessed environmental exposure levels at fire stations and the urinary levels of one or more PAH metabolites. Furthermore, urinary 10HAce, 2OHFlu, and $30 \mathrm{HB}[\mathrm{a}] \mathrm{P}$ were never measured before in firefighters.

Thus, the present study aims to assess the levels of 18 PAHs (16 USEPA priority PAHs, dibenzo[a,l]pyrene, and benzo[j]fluoranthene recommended by EU [40]) in the breathing air zone of firefighters' during their work shift at Portuguese fire stations, and the firefighters' total internal dose by six biomarkers of exposure (1OHNaph, 1OHAce, 2OHFlu, 1OHPhen, 1OHPy, and 3OHB[a]P) in urine samples. The contribution of personal airborne individual (naphthalene, acenaphthene, naphthalene + acenaphthene, fluorene, phenanthrene, pyrene) and $\Sigma$ PAHs exposure to respective individual (10HNaph +10HAce, 2OHFlu, 1OHPhen, and 1OHPy) and $\Sigma \mathrm{OH}-\mathrm{PAHs}$ excretion in urine was explored for the first time in firefighters.

\section{Materials and Methods}

\subsection{Characterization of the sampling sites}

Portugal is one of the five Southern European countries that are the most affected by forest fires every year [41], being the North and Centre regions the most disturbed areas [42]. In 2014 the district of Bragança, in the sub-region of Alto Trás-os-Montes, (north of Portugal), was the third Portuguese district with a higher incidence of burnt area [42]. This region is characterized by typically hot and very dry summers with absolute maximum temperatures exceeding the $30^{\circ} \mathrm{C}$; winters are usually long and cold with absolute minimum temperatures reaching values below $0{ }^{\circ} \mathrm{C}$. Sampling was performed at eight different fire stations: Miranda do Douro (MRD), Torre Dona Chama (TDC), Sendim (SDM), Mirandela (MDL), Torre de Moncorvo (TMC), Vinhais (VNH), Bragança (BRG), and Freixo de Espada à Cinta (FEC) (Fig. 1). Two pairs of fire stations, namely MDL and TDC, as well as MRD and SDM were $22-23 \mathrm{~km}$ away from each other. The fire stations FEC, MDL, and MRD were located in the urban center of the city, near commercial shops and busy roads, while the firehouses TMC and TDC were situated in villages. FEC, MDL, and MRD were constructed before 1984 while the other fire stations were constructed and/or restored after 2007. At FEC, MDL and MRD, the truck bay where firefighters' and emergency vehicles were parked on had direct access to the operational control center and social room where firefighters spend most of their time (Fig. 1S (a), Supplementary Material). The door that separated these two microenvironments was frequently opened. At fire stations TDC, SDM, TMC, VNH, and BRG, the control center and social room were indirectly (through corridors and with some divisions; Fig. 1S (b), Supplementary Material) connected with the truck bay.

Information on outdoor meteorological conditions, namely temperature, relative humidity, wind speed, precipitation, and solar radiation during the sampling campaigns were retrieved from the local meteorological station (Table 1S, Supplementary material). The concentrations of 24-h ambient particulate matter with aero- 


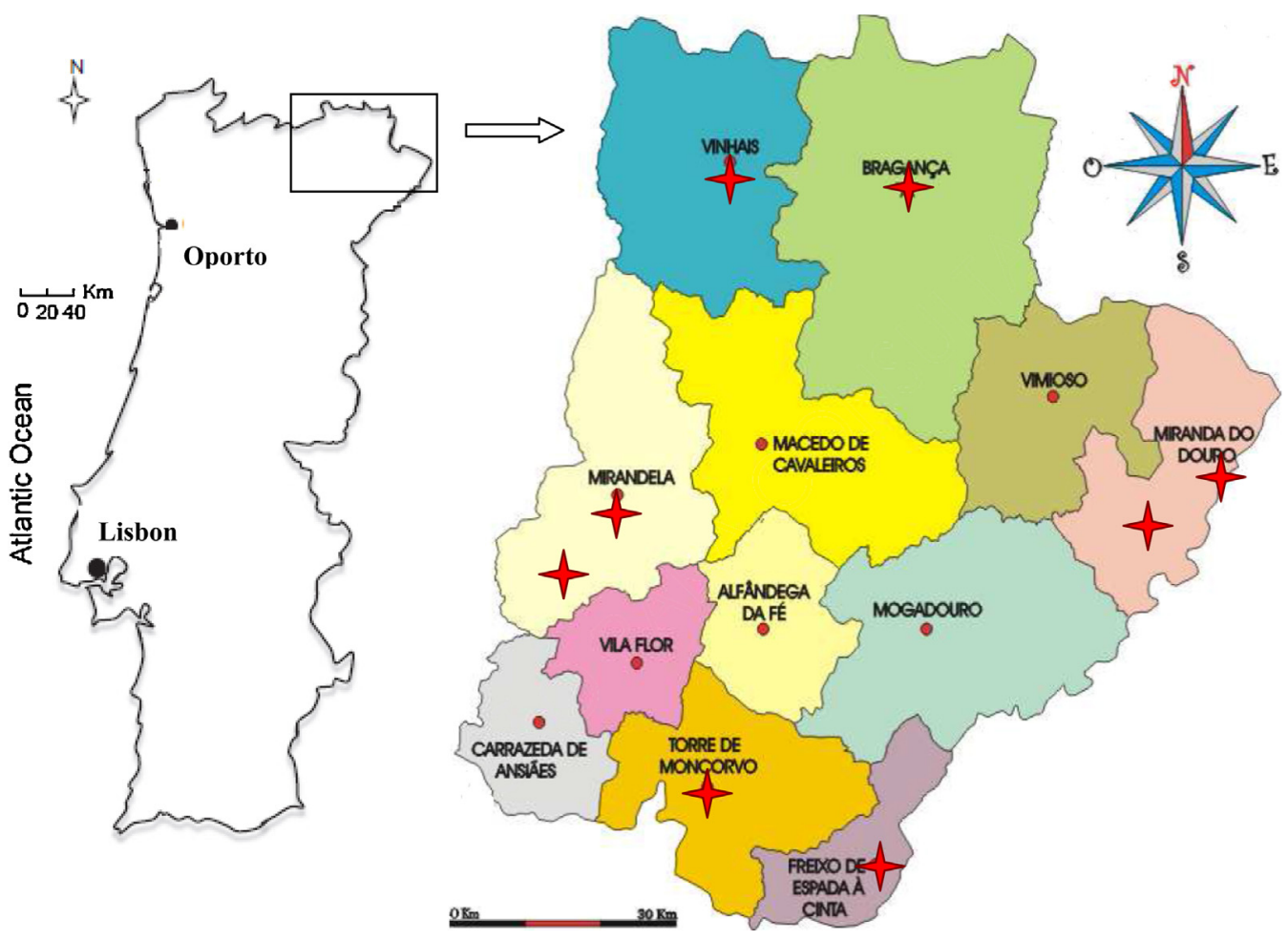

Fig. 1. Geographical location of the monitored fire stations in the district of Bragança.

dynamic diameter of $10 \mu \mathrm{m}\left(\mathrm{PM}_{10}\right)$ and $2.5 \mu \mathrm{m}\left(\mathrm{PM}_{2.5}\right)$, nitrogen monoxide (NO), dioxide $\left(\mathrm{NO}_{2}\right)$ and oxides (NOx), sulphur dioxide $\left(\mathrm{SO}_{2}\right)$, and ozone $\left(\mathrm{O}_{3}\right)$ were also monitored from the meteorological station during the sampling campaign (Table 1S, Supplementary material).

\subsection{Personal air and urine sampling}

The study population consisted of eight units of professional firefighters serving at six municipal cities (Fig. 1). A structured questionnaire adapted from validated questionnaire [43] was filled by each firefighter. The questionnaire collected information on gender, age, number of years as firefighter (Table 2S, Supplementary material), and factors reported to be associated with PAH exposures, namely smoking habits, and the most consumed meals (boiled, roasted, and grilled) during the five days before urine collection. Subjects were excluded from the study if they participated in firefighting activities within five days prior the sampling campaigns and if they were exposed to tobacco smoke. Based on the information collected through the individual questionnaires, PAHs intake through food ingestion was considered not significant. All participants read and signed informed consent forms approved by the Ethic Committee of University of Porto.

Personal exposures were monitored during a period of fiftyfour days (June and July 2014) in firefighters that were not directly involved in firefighting activities. At each fire station, air sampling campaigns of 18 selected PAHs in $\mathrm{PM}_{2.5}$ were performed on a single day (6 individuals at SDM and FEC; 9 at MRD, MDL and TMC; 12 at TDC, VNH and BRG) and over a continuous 4-h period of a regular work shift inside the fire station; duplicate samples per individual were collected. During the sampling campaign firefighters were encouraged to move freely at the fire station as in a normal working day. Air sampling was done by personal constant flow samplers (Gilian, models GilAir3 and ProValue3; Sensidyne, USA) that were placed at the waist of each firefighter in a way that could not disturb the regular activities; an air flow rate of $2 \mathrm{~L} / \mathrm{min}$ was used. The inlets were positioned at the breading zone of firefighters. Air samples were collected on polytetrafluoroethylene membrane filters with polymethylpentene support ring ( $2 \mu \mathrm{m}$ porosity, $\varnothing 47 \mathrm{~mm}$, SKC Ltd., United Kingdom). $\mathrm{PM}_{2.5}$ masses were determined gravimetrically according to [44]. After the sampling, filters were stored in a freezer $\left(-20^{\circ} \mathrm{C}\right)$ before chemical analysis.

A spot urine sample was collected at the end of the firefighter work shift in sterilized $50 \mathrm{~mL}$ polycarbonate containers. Samples were frozen at $-20^{\circ} \mathrm{C}$ until analysis. Sampling campaigns were performed in triplicate.

During sample collection, a researcher was present to keep a record of potential source activities and ventilation system status (door and window positions). Potential sources of PAHs in each fire station were also collected. It was observed that during sampling campaigns, there were always vehicles (arriving, parking, or leaving) on the truck bay; smoking is not allowed at fire stations.

\subsection{PAHs and $\mathrm{OH}-\mathrm{PAHs}$ chromatographic analysis}

Extraction and quantification of PAHs from $\mathrm{PM}_{2.5}$ filters, and $\mathrm{OH}-\mathrm{PAHs}$ from urine samples were performed by previously validated analytical procedures [45-47]. PAHs and OH-PAHs extracts were analysed using a Shimadzu LC system (Shimadzu Corporation, Kyoto, Japan) equipped with photodiode array (PAD) and fluorescence (FLD) detectors on line. Separation of the compounds was performed in a C18 column (CC 150/4 Nucleosil 100-5C18 $\mathrm{PAH}, 150 \times 4.0 \mathrm{~mm}$; $5 \mu \mathrm{m}$ particle size; Macherey-Nagel, Duren, Germany) maintained at room temperature $\left(20 \pm 1^{\circ} \mathrm{C}\right)$. Fluorescence wavelength programming was used to perform better sensitivity and minimal interference. Each compound was detected at its optimum excitation/emission wavelength pair: $260 / 315 \mathrm{~nm}$ (naphthalene, acenaphthene and fluorene), 260/366 nm (phenanthrene), $260 / 430 \mathrm{~nm}$ (anthracene, fluoranthene, pyrene, benz[a]anthracene, chrysene, benzo[b+j]fluoranthene, benzo[k]fluoranthene, benzo[a]pyrene, dibenz[a,h]anthracene, benzo[ghi]perylene and dibenzo[a,l]pyrene), and 290/505 nm 


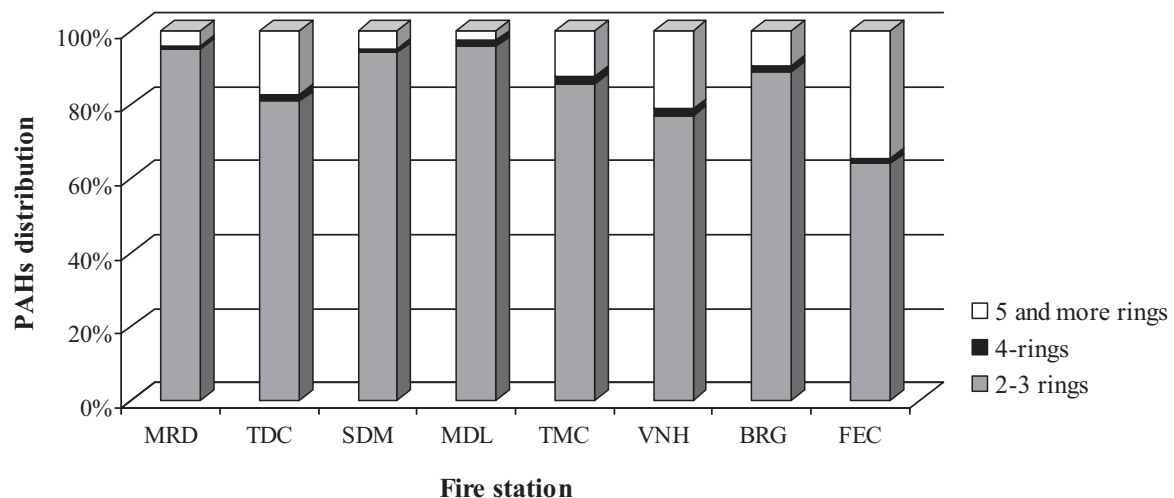

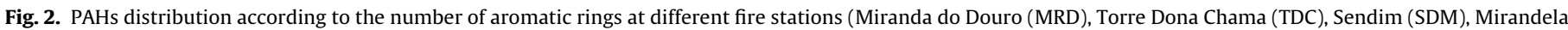
(MDL), Torre de Moncorvo (TMC), Vinhais (VNH), Bragança (BRG), and Freixo de Espada à Cinta (FEC)).

(indeno[1,2,3-cd]pyrene) for PAHs, and 232/337 nm (10HNapt and 1OHAce), 265/335 nm (2OHFlu), 263/363 nm (10HPhen), 242/388 nm (10HPy), and 308/432 nm (30HB[a]P) for OH-PAHs. The PAH acenaphthylene, which shows limited fluorescence, was analysed at $254 \mathrm{~nm}$ in PAD.

Calibrations with PAHs and OH-PAHs mixed standards, using at least 6 calibration points, were performed in acetonitrile and methanol, respectively. Calibration curves were linearly fitted with correlation coefficients always higher than 0.9979. RSD values ranged from 1.8\% (dibenzo[a,l]pyrene) to 9.1\% (naphthalene) for PAHs extraction from filters. Regarding urinary OH-PAHs, RSD values varied between 1.3\% (10HNaph + 10HAce and 20 HFlu ) to $8.1 \%$ (10HNaph +10HAce, 2OHFlu, and 10HPy). Limits of detection (LODs) and quantification (LOQs) were calculated as the minimum detectable amount of analyte with a signal-to-noise ratio of 3:1 and 10:1, respectively [48]. For PAHs, LODs between $1.0 \mathrm{pg} / \mathrm{m}^{3}$ (for anthracene, benzo[k]fluoranthene, chrysene, benz[a]anthracene, phenanthrene and indeno[1,2,3cd]pyrene) and $148 \mathrm{pg} / \mathrm{m}^{3}$ (for acenaphthylene) were obtained, with corresponding LOQs in the range $3.4-492 \mathrm{pg} / \mathrm{m}^{3}$. Regarding OH-PAHs, LODs ranged between $0.0008 \mu \mathrm{g} / \mathrm{L}$ urine (for 2OHFlu) to $0.195 \mu \mathrm{g} / \mathrm{L}$ urine (for 1 OHNaph +1 OHAce), while the respective LOQs varied from $0.0028 \mu \mathrm{g} / \mathrm{L}$ urine to $0.650 \mu \mathrm{g} / \mathrm{L}$ urine.

All OH-PAH concentrations were normalized by urinary creatinine $(\mathrm{mol} / \mathrm{mol})$. Urinary creatinine measurements were performed according to the Jaffe colorimetric method [49].

Analytical blanks and standards were analysed daily and regularly. Each analysis was performed at least in triplicate.

\subsection{Statistical analysis}

Statistical analysis was performed using SPSS (IBM SPSS Statistics 20). PAHs and OH-PAHs median values were compared through the nonparametric Mann-Whitney $U$ test, since normal distribution was not observed by Kolmogorov-Smirnov with Lilliefors correction and Shapiro-Wilk's tests. When the concentration was below the LOD, the value of the respective LOD $/ \sqrt{ } 2$ was used [50]. Statistical significance was defined as $p \leq 0.05$. Spearman correlation coefficients were calculated to examine the relation between airborne individual and total PAH concentrations with firefighters' urinary individual and total OH-PAHs for each fire station.

\section{Results and Discussion}

\subsection{Personal exposure monitoring}

The concentrations of individual and total PAHs ( $\Sigma$ PAHs) in the breathing air zone of firefighters working at each fire station are presented in Table 1 . Among the 18 PAHs considered, acenaphthylene was the most abundant compound (except in the environmental exposures of the rural sites of TMC and TDC where it was not detected) with concentrations representing $46.4 \%$ (at FEC) to $61.5 \%$ (at SDM) of $\Sigma$ PAHs. Acenaphthylene is a component of crude oil, coal tar, tobacco smoke and a product of combustion which may be produced and released to the environment during fires $[20,30,51]$; emissions from wood combustion contain more acenaphthylene than other PAHs [52]. For workers at MRD, SDM, MDL, TMC, and BRG firehouses, the other most abundant PAHs were, by descending order, acenaphthene, naphthalene, and phenanthrene with contributions ranging from 15.5 (BRG) to 38.6\% (MRD), 4.48 (MDL) to 16.8\% (BRG), and from 2.65 (MRD) to $7.82 \%$ (TMC), respectively. Together with acenaphthylene, these four $\mathrm{PM}_{2.5}$-bound PAHs represented 84.6-95.0\% of $\Sigma$ PAHs for those fire stations. In the breathing air zone of firefighters from FEC and $\mathrm{VNH}$, dibenz[a,h]anthracene was respectively the second and third predominant $\mathrm{PAH}$, accounting with $11.9 \%$ and $7.84 \%$ of $\Sigma \mathrm{PAHs}$. Dibenz[a,h]anthracene concentrations in workers from the remaining six fire stations represented only $0.30-1.73 \%$ of $\Sigma$ PAHs. The prevalence of this compound indicates a higher influence from light-duty gasoline vehicle emissions [53] in the surrounding areas of FEC and VNH fire stations. Globally $\mathrm{PM}_{2.5}$-bound PAHs with 2-3 aromatic rings (naphthalene, acenaphthylene, and acenaphthene) represented $63.9 \%$ (FEC) to $95.7 \%$ (MDL) of $\Sigma$ PAHs; 4 aromatic ring compounds (anthracene, fluoranthene, and pyrene) accounted with $0.79 \%$ (MRD) to $2.05 \%$ (TMC) and 5 or more aromatic ring PAHs corresponded to $2.74 \%$ (MDL) to $34.7 \%$ (FEC) of $\Sigma$ PAHs (Fig. 2). It is worth to mention that lighter PAHs usually predominate in the gas phase $[10,36]$ suggesting that the determined personal exposures may be underestimated. Overall airborne PAH profiles obtained at FEC and VNH exhibited the highest contributions of the heavier molecular weight compounds (the most hazardous), while those at MRD, SDM and MDL presented the lowest. As a general rule, PAHs toxicity increases as the number of rings increases (with the exception of naphthalene, 2-rings compound that is classified as possible human carcinogen; [8]).

Global mean $\Sigma$ PAHs varied widely. The highest total median content of PAHs was found, by descending order, in the breathing air zone of firefighters from FEC " $M D L>M R D$ » $\mathrm{SDM}>\mathrm{VNH}>\mathrm{BRG}>\mathrm{TMC} \approx \mathrm{TDC}$, with levels at FEC $\left(428 \mathrm{ng} / \mathrm{m}^{3}\right) 2$ $\left(256 \mathrm{ng} / \mathrm{m}^{3}, \mathrm{MDL}\right)$ to $9\left(46.4 \mathrm{ng} / \mathrm{m}^{3}, \mathrm{TDC}\right)$ times significantly higher $(p \leq 0.036)$ than at the other fire houses. Indoor PAH levels, and personal exposure, depend on activities conducted, occupancy rates, physical characteristics of buildings (permeability, particle sizespecific difference), site specificity, ventilation habits, season and meteorology. The observed differences may be mainly attributed to site specificity (urban/rural) and characteristics of buildings. The 


\section{$\square$ EPAHscar $\quad \square$ PPAHs}

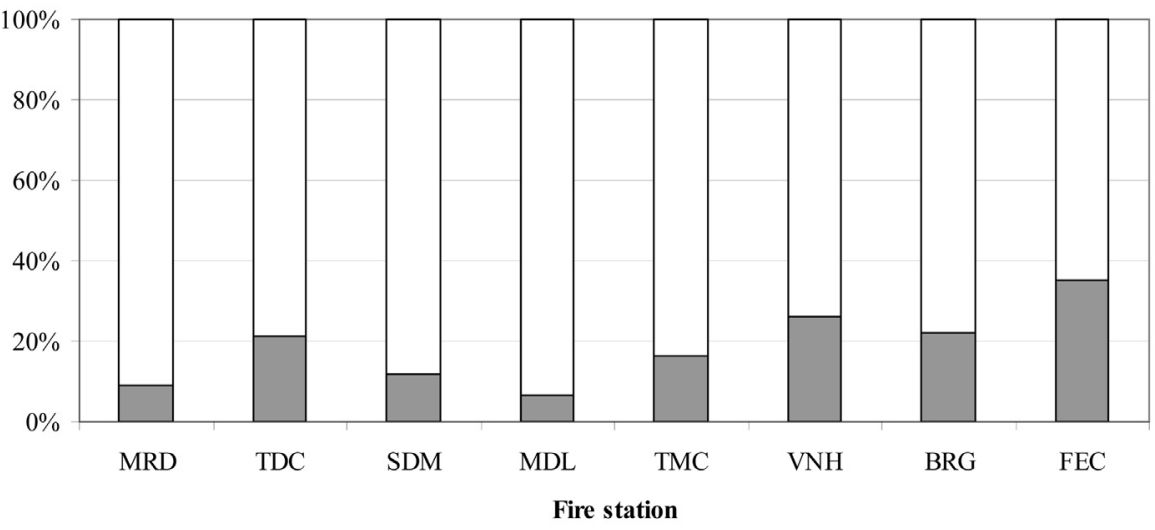

(a)

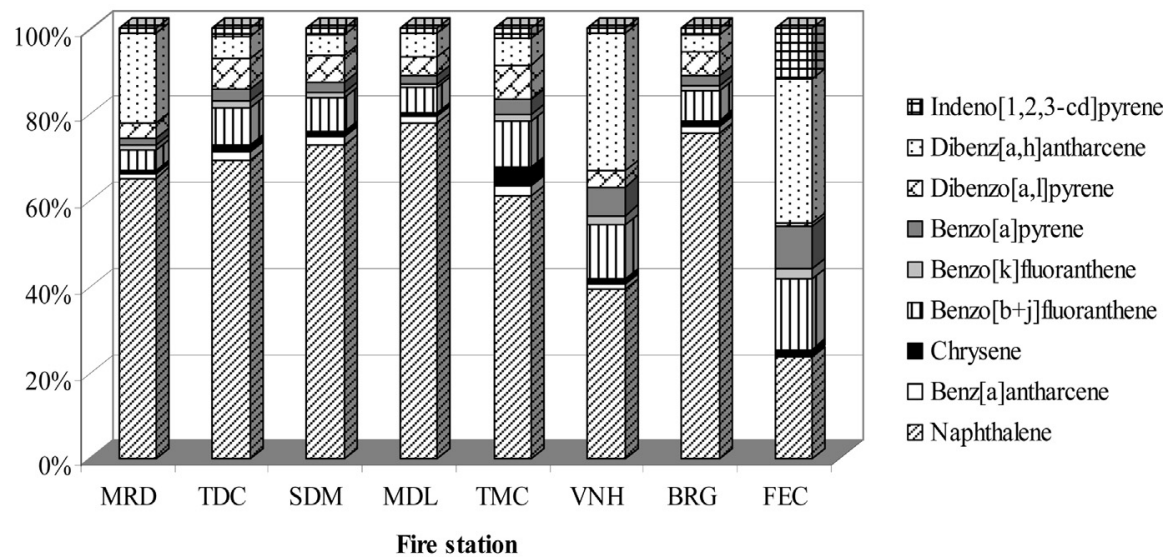

(b)

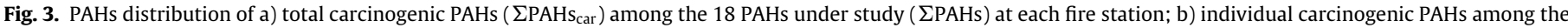

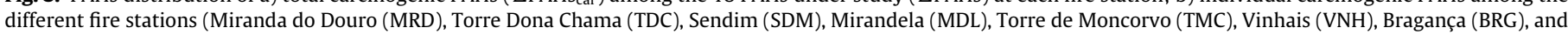
Freixo de Espada à Cinta (FEC))

two firehouses located at rural areas with low traffic influences (TMC and TDC) presented the lowest levels of PAHs in the breathing air zone of firefighters (Table 1 ), followed by those situated in urban sites but constructed and/or restored more recently (BGR, VNH and SDM). Vehicular traffic emissions are one of the major sources of PAHs in urban areas [54]. In addition, the age of a building reflects its condition and affects penetration of outdoor PAH concentrations to indoor air. The older a building, the greater will be the impact of outdoor sources owing to higher air exchange through such routes as poorly fitting windows and doors [55]. The urban location (near busy roads), building age (constructed before 1984) and lay-out of FEC, MDL, and MRD contributed significantly to the elevated firefighters' environmental exposure at these firehouses. The truck bay at FEC, MDL and MRD was physically separated from the operational control center and social room (where firefighters spend most of their time) only by a door (that was frequently opened). Moreover, the determined levels at these three stations were higher than those reported $\left(30.5-126.5 \mathrm{ng} / \mathrm{m}^{3}\right)$ for two sites located in the outskirts of the city of Porto that is a more urbanized area and has much higher traffic density than Bragança district (Metropolitan Area of Porto has $2042 \mathrm{~km}^{2}$ with 1.7 million citizens, while Bragança district has an area of $6608 \mathrm{~km}^{2}$ with 139344 citizens); Porto district corresponds to the nearest geographical region (Fig. 1) that was previously characterized in terms of atmospheric PAH levels [56].
More detailed analysis was performed concerning the carcinogenic PAHs ( $\Sigma$ PAHs $_{\mathrm{car}}$; Table 1 ). The inter-fire stations comparison of the content of $\Sigma \mathrm{PAHs}_{\mathrm{car}}$ in the breathing air zone of firefighters was $\mathrm{FEC}$ » $\mathrm{MRD} \approx \mathrm{VNH}>\mathrm{MDL}>\mathrm{BRG} \approx \mathrm{SDM} \approx \mathrm{TDC} \approx \mathrm{TMC}$. In accordance with the $\Sigma$ PAH levels, workers from FEC exhibited significantly higher $(p \leq 0.002) \Sigma P A H s_{\text {car }}$ (Fig. 3a). Globally the compound that contributed the most to $\Sigma \mathrm{PAHs}_{\mathrm{car}}$ was naphthalene (39.4\% at VNH to $78.1 \%$ at MDL), except for firefighters from FEC firehouse. For that fire station, dibenz[a,h]anthracene (with a toxicity equivalent factor 5 times higher than benzo[a]pyrene; [9] was the predominant PAH accounting with $33.8 \%$ of $\Sigma \mathrm{PAHs}$ car, followed by naphthalene (23.5\%) (Fig. 3b). In addition, firefighters working at $\mathrm{VNH}$ firehouse also presented a relevant contribution of dibenz[a,h]anthracene $\left(32.1 \%\right.$ of $\left.\Sigma \mathrm{PAHs}_{\mathrm{car}}\right)$ in their breathing air zone; for the other sites, values varied from $4.1 \%$ (BRG) to $21.1 \%$ (MRD) of $\Sigma \mathrm{PAHs}_{\mathrm{car}}$. The maximum concentrations of benzo[a]pyrene, the PAHs marker of carcinogenicity, accounted with $10 \%$ at FEC, $6.7 \%$ at $\mathrm{VNH}, 1.5-3.4 \%$ of $\Sigma \mathrm{PAHs}$ car for the other firehouses (Fig. 3b). Furthermore, it is important to mention that the median concentrations of benzo[a]pyrene of FEC firefighters exceeded 10 to 20 times the existent limit value of $1 \mathrm{ng} / \mathrm{m}^{3}$ (annual mean total content in $\mathrm{PM}_{10}$ fraction) for ambient air [40]. Dibenzo[a,l]pyrene, which carcinogenic potency has been estimated to be approximately 100 times that of benzo[a]pyrene [9], presented concentrations lower than $0.671 \mathrm{ng} / \mathrm{m}^{3}(0.44-8.2 \%$ of $\Sigma \mathrm{PAHs}_{\mathrm{car}}$ ) in the breathing air zone of firefighters. 

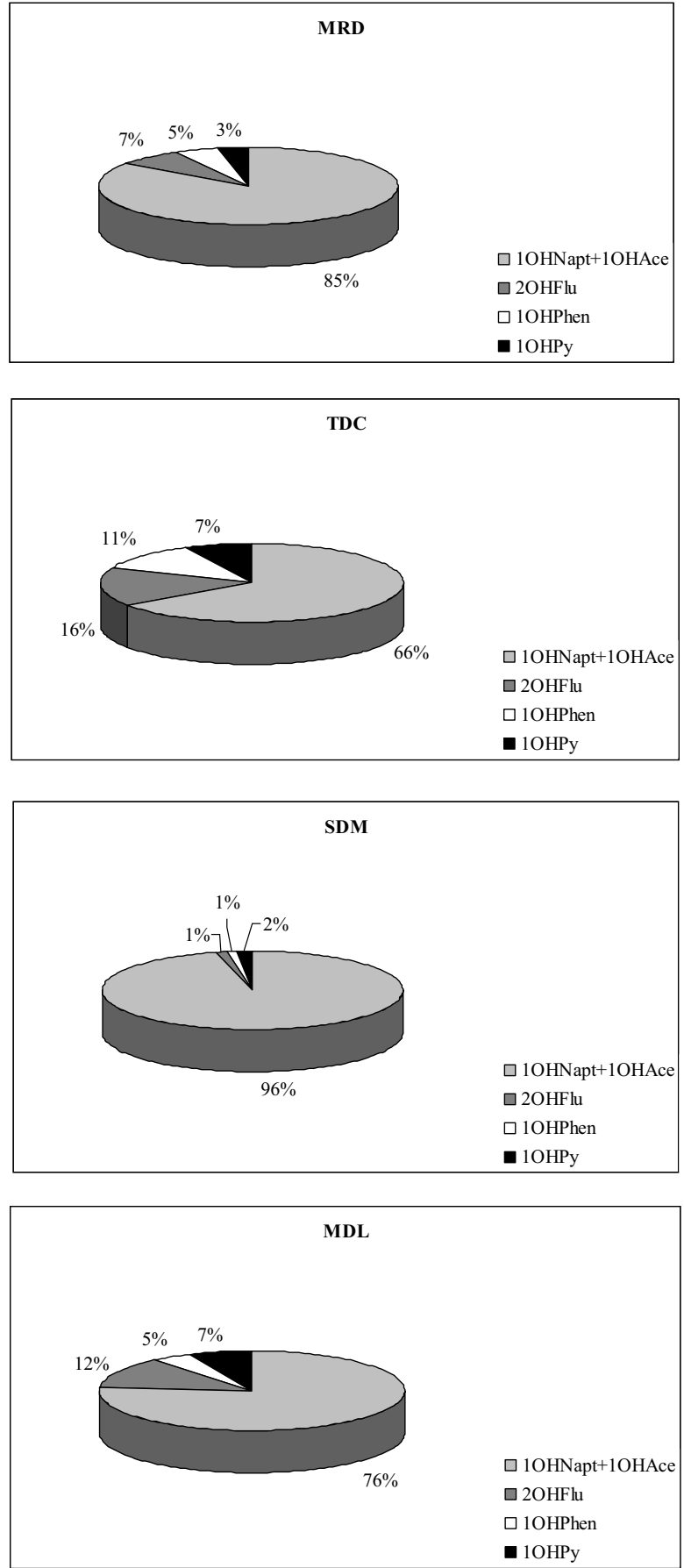
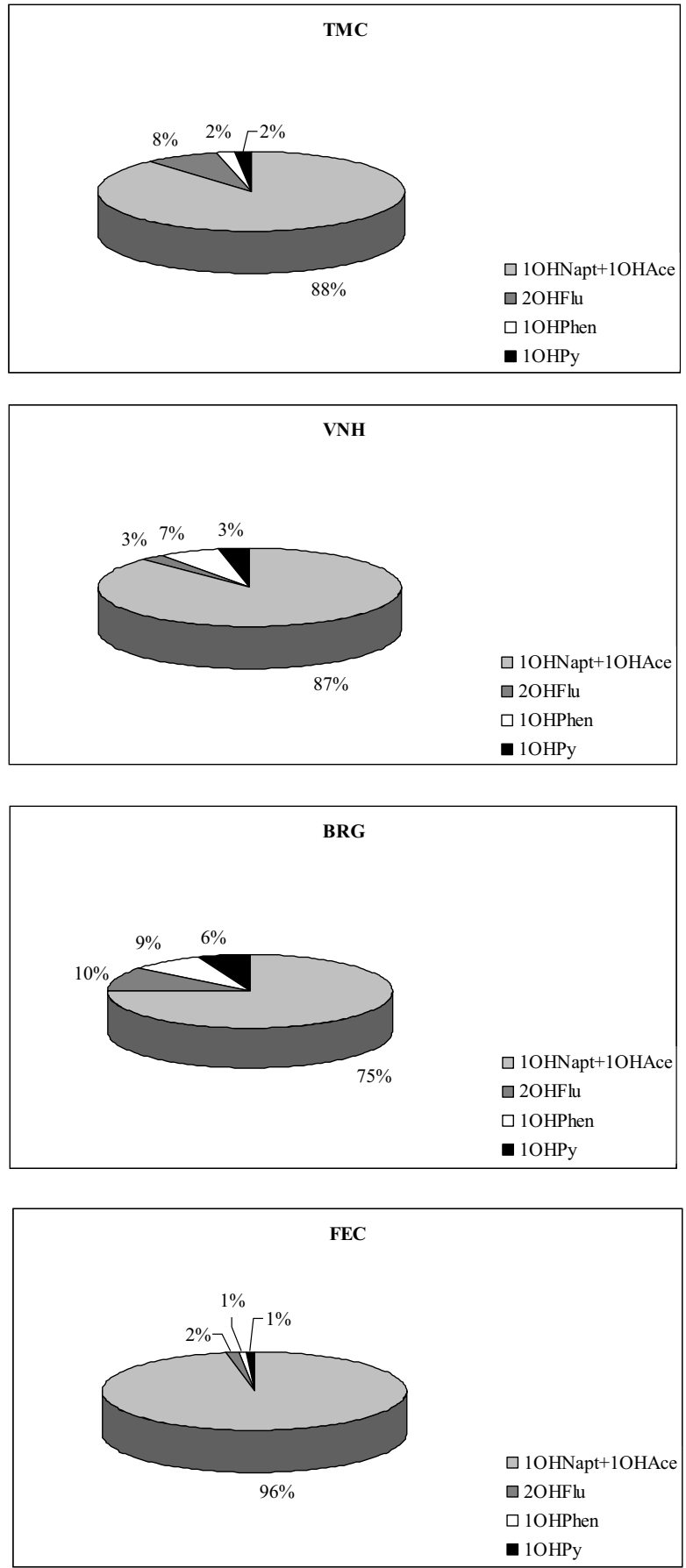

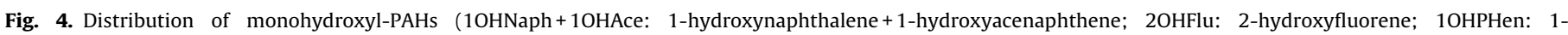

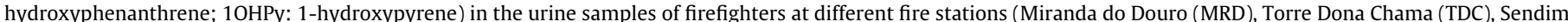
(SDM), Mirandela (MDL), Torre de Moncorvo (TMC), Vinhais (VNH), Bragança (BRG), and Freixo de Espada à Cinta (FEC)).

Firefighters personal exposure to PAHs at Portuguese fire stations were well below the existent PAHs occupational exposure limits proposed by the American Conference of Governmental Industrial Hygienists (ACGIH), the NIOSH and the US Occupational Safety and Health Administration (OSHA) (Table 3S, Supplementary material).

Studies regarding firefighters' occupational exposure to PAHs at fire stations are very scarce [23,32]; none in European facilities. Moreover, comparison between various studies is hampered by different designs (analysed particulate fraction or/and number of determined PAHs). Shen and coworkers [32] collected dust samples from vacuum cleaner bags used to routinely clean twenty American firehouses. Median total PAHs concentration in dust was $4124 \mathrm{ng} / \mathrm{g}$. Among the 10 compounds under study, pyrene was the predominant $\mathrm{PAH}$ measured in these dust samples, followed, in decreasing order, by benzo[ghi]perylene, fluoranthene and chrysene. Baxter and colleagues [23] conducted an air monitoring study in three different environments, including in the fire truck bay and equipment storage area, the kitchen/common area, and the sleeping quarters of two American fire stations [23]. Surprisingly, out of 16 quantified PAHs, only naphthalene (at $9.22-9.24 \mu \mathrm{g} / \mathrm{m}^{3}$ ) was detected in $\mathrm{PM}_{2.5}$-bound PAHs samples collected in the kitchen and 
truck bay of one firehouse. Median concentrations of naphthalene (4.95 at TMC to $12.2 \mathrm{ng} / \mathrm{m}^{3}$ at MRD, Table 1 ) in the breathing air zone of Portuguese firefighters were lower than those reported levels [23]. Furthermore, some recent studies $[20,30]$ have reported that a quantifiable deposition of PAHs outside and inside firefighters' ensembles (helmets, gloves, hoods, and turnout gear) occurs which may significantly contribute to total PAHs body burden. Further research is required to investigate this aspect.

\subsection{Biomonitoring}

Biomonitoring of firefighters is an effective assessment tool to understand total exposures, especially to compounds such as PAHs that are not absorbed exclusively by inhalation, but also through dermal contact and food ingestion [18-20]. Median concentrations of individual and total OH-PAHs ( $\Sigma \mathrm{OH}-\mathrm{PAHs}$ ) in the urine samples of firefighters are presented in Table 2. Urinary OH-PAH levels were normalized by the creatinine levels of each firefighter. Globally creatinine concentrations in the urine of firefighters ranged between 0.82 to $2.74 \mathrm{~g} / \mathrm{L}$, being within the accepted creatinine range for healthy people $(>0.3$ and $<3 \mathrm{~g} / \mathrm{L})$ [57]. Since PAHs are ubiquitous pollutants, each participating firefighter was requested to fill a questionnaire regarding the existence of possible exposure to PAHs outside the occupational environment. Only non-smoking firefighters with dietary exclusive of barbecue and deep-fried foods within five days before urine samples collection were considered. Thus, it was assumed that firefighters had similar (non-significant) levels of PAHs exposure through food consumption and that tobacco smoke contribution was negligible. Still, the assessment of tobacco biomarker data, and the use of pre-exposure urine samples, would be precious to validate these assumptions. Knowledge of the elimination kinetics of the urinary OH-PAHs is essential to define the urine sampling strategy. Limited studies regarding elimination kinetics of OH-PAHs in humans are available: half-life of urinary 1OHPy excretion rates varies between 6 to $35 \mathrm{~h}$ after inhalation exposure [58,59] and 4.4 [60] to $12 \mathrm{~h}$ [61] after ingestion exposure; half-life ranging from 3.3 to $6.2 \mathrm{~h}$ for $10 \mathrm{HNaph}, 2.3$ to $4.0 \mathrm{~h}$ for $2 \mathrm{OHFlu}$, and 4.3 to $6.1 \mathrm{~h}$ for 1-OHPhen were also reported for ingestion exposure [37]. 10HNaph $+10 H A c e$ were detected in more than $87 \%$ of samples, 2 -OHFlu and $10 H$ Py presented detection rates above $96 \%$ and $10 H P h e n$ was detected in all urine samples. In agreement with some previous studies, urinary 30HB[a]P (metabolite of the PAH marker of carcinogenicity) presented null or very low detection rates $[37,62,63]$. Some studies with animals revealed that urinary concentrations of $3 \mathrm{OHB}$ [a]P represent only $0.1-0.2 \%$ of the benzo[a]pyrene dose, due to a complex metabolism that produces several different metabolites which are mainly excreted in feces [64].

Overall the inter-comparison of urinary $\Sigma \mathrm{OH}-\mathrm{PAHs}$ of firefighters from fire stations: $\mathrm{FEC}$ " VNH $>\mathrm{MRD} \approx \mathrm{SDM}>\mathrm{MDL}>\mathrm{BRG}>\mathrm{TMC}$ » TDC, followed the same trend as the content of airborne $\Sigma$ PAHs with the exception of workers from VNH and MDL that exchanged position. Accordingly, urinary $\Sigma \mathrm{OH}-\mathrm{PAHs}$ in individuals from FEC were significantly elevated ( $p \leq 0.002$ ) (2 (MRD) to 14 (TDC) times higher) than at other firehouses. The concentrations of urinary $\mathrm{OH}-\mathrm{PAHs}$ in firefighters were inversely related to the size of compounds, i.e., the higher the molecular weight the lower the detected $\mathrm{OH}-\mathrm{PAH}$ concentrations (Table 2). Urinary $10 \mathrm{HNaph}+1 \mathrm{OHAce}$ were by far the predominant compounds accounting with $66 \%$ (TDC) to $96 \%$ of $\Sigma$ OH-PAHs (FEC, SDM), being followed by $20 \mathrm{HFlu}$ ( $1 \%$ at SDM to $16 \%$ at TDC), 10 HPhen (1\% at SDM and FEC to $11 \%$ at TDC), and 10HPy (1\% at FEC to $7 \%$ at TDC) (Fig. 4). This distribution profile follows the same pattern as the PAHs distribution in the breathing air zone of firefighters while working at fire stations (Table 1); airborne PAHs with two and three aromatic rings were the most abundant ones in all fire stations (63.9\% at FEC to
95.7\% of $\Sigma$ PAHs at MDL, Fig. 2). Urinary 10HNaph + 10HAce concentrations were significantly different $(p \leq 0.002)$ from the other metabolites for all groups of individuals (Table 2). The median concentrations of urinary $10 \mathrm{HPy}$ in Portuguese firefighters ranged between $1.36 \times 10^{-2}$ (SDM) to 0.146 (MDL) $\mu \mathrm{mol} / \mathrm{mol}$ creatinine (Table 2). Nowadays, measurements of urinary $10 H P y$ are routinely applied to control industrial exposure to PAHs in coke ovens and primary aluminum production and to control exposure of professionals when handling coal tar derived products [34]. Although no reference standard guidelines are established for urinary $\mathrm{OH}$ PAHs, Jongeneelen $[33,34]$ proposed a no-biological effect level of $1.4 \mu \mathrm{mol} / \mathrm{mol}$ creatinine of 1-hydroxypyrene in urine of exposed workers, i.e. the lowest reported level at which no genotoxic effects were found. In addition the Biological Exposure Index Committee of ACGIH stated that the presence of urinary 1OHPy above a benchmark level of about $1 \mu \mathrm{g} / \mathrm{L}(0.5 \mu \mathrm{mol} / \mathrm{mol})$ indicates occupational exposure to PAHs, since very few non-occupationally exposed persons, smokers or non-smokers, will excrete this amount of 1OHPy [65]. ACGIH also recommends that the benchmark should be considered as a post-shift level. The quantified concentrations of post-shift urinary 10HPy in firefighters from all fire stations were well below those recommended values. This observation is important since firefighters participating at firefighting activities are heavily exposed to PAHs [18-20] and thus may present high background levels of 1OHPy.

Regarding characterization of firefighters' exposure, 10HPy and 1OHNaph are the more investigated metabolites [27,31,38,39]. The comparison of the detected levels with previous reports is extremely difficult since, in the majority of the studies, concentrations are not adequately normalized with the personal urinary creatinine levels. Creatinine is eliminated from the human body at a constant rate, and thus is widely used to minimize the variability of parameters such as individual fluid intake, body temperature, physical exercise and ambient temperature, which changes from person to person. Still, urinary 10HPy concentrations in Portuguese firefighters (overall range: $0.078-3.28 \mathrm{nmol} / \mathrm{L}$ ) were slightly higher than levels found in firefighters before their participation in gas simulators (0.6-1.2 nmol/L) but lower than concentrations at diving simulator fires (0.6-9.2 nmol/L) [32]. In addition 1OHPy levels were similar with the levels reported in firefighters before their participation in prescribed pile burns $(<0.01-0.56 \mu \mathrm{g} / \mathrm{L}$ [27]) but slightly higher than the concentrations observed in the control group of firefighters that were present at the World Trade Center Collapse in 2001 (157 ng/L in this study versus $62.5 \mathrm{ng} / \mathrm{L}$ [39]). Only two studies reported concentrations of other metabolites, namely several OHPhen [39] and 1OHNaph [31] compounds among firefighter's urine. Urinary 10HPhen levels were similar with those observed in the control group of firefighters $(170 \mathrm{ng} / \mathrm{L}$ in this study versus $158 \mathrm{ng} / \mathrm{L}$ [39]). In firefighters, urinary 1OHAce, 2OHFlu, and $3 \mathrm{OHB}[\mathrm{a}] \mathrm{P}$ were never assessed before. Urinary OH-PAHs excretion in firefighters during their regular work at fire stations was lower than levels reported for other industrial workers with known PAHs exposure [63,66-70].

\subsection{Correlations between airborne PAHs and urinary $\mathrm{OH}-\mathrm{PAHS}$}

The possible contribution of airborne individual (naphthalene, acenaphthene, naphthalene+acenaphthene, fluorene, phenanthrene, and pyrene) and $\Sigma \mathrm{PAHs}$ to respective individual (10HNaph + 1OHAce, 2OHFlu, 10HPhen, and 1OHPy) and $\mathrm{\Sigma OH}-$ PAHs excretion in the post-shift urine was estimated. Moderate to strong correlations were observed between $\Sigma$ PAHs and urinary $\Sigma$ OH-PAHs (ranging from $r=0.367, p=0.332$ at TMC to $r=0.886$, $p=0.019$ at FEC) for firefighters from six fire stations (FEC, BRG, MDL, MRD, TDC, TMC); statistical significance was reached for workers from $\operatorname{MRD}(r=0.733, p=0.025), \operatorname{MDL}(r=0.786, p=0.021)$, 
BRG $(r=0.839, p=0.001)$ and FEC $(r=0.886, p=0.019)$ which were three of the firehouses where the highest environmental exposure were detected (Table 1 ).

These findings are in agreement with those described for coke oven workers $(\mathrm{r}=0.680, p \leq 0.01$ between $\Sigma$ PAHs of 15 compounds and $\Sigma \mathrm{OH}-\mathrm{PAHs}$ of 10 metabolites) [61]. The positive correlations confirm that $\mathrm{OH}-\mathrm{PAH}$ excretion increases with an increasing exposure of PAHs at fire stations. It seems that, at these sites, firefighters had fire station indoor air as their major exposure source of PAHs. Also, $\mathrm{EPAHs}$ correlated well with $1 \mathrm{OHPy}$, the biomarker of PAHs exposure, for individuals from MRD $(r=0.703$, $p=0.035)$, SDM $(r=0.941, p=0.005), \operatorname{MDL}(r=0.262, p=0.531)$ and VNH $(r=0.944, p \leq 0.001)$. These urban sites are in the list of the 5 firehouses where environmental PAHs exposure were the highest ( FEC » $\mathrm{MDL}>\mathrm{MRD}$ » $\mathrm{SDM}>\mathrm{VNH}>\mathrm{BRG}>\mathrm{TMC} \approx \mathrm{TDC}$; Table 1 ); the only observed exception was FEC. These results suggest that $1 \mathrm{OHPy}$ may be a suitable biological indicator of internal dose of exposure to those PAHs that are emitted by the predominant source. These correlations are higher than those reported in coke oven workers $(r=0.456, p<0.01$; [63]) but similar with the relationships described in workers employed in coke production, production of graphite electrodes, special carbon products, and production of refractory materials $(r=0.717, p<0.01)$ [70]. Other significant relationships were reached between naphthalene + acenaphthene with urinary $10 \mathrm{HNaph}+1 \mathrm{OHAce}$ for firefighters at MDL $(\mathrm{r}=0.833$, $p=0.010)$, fluorene and 2OHFlu at FEC $(r=0.771, p=0.072)$ and BRG $(\mathrm{r}=0.736, p=0.006)$, phenanthrene and 10HPhen at $\mathrm{FEC}(\mathrm{r}=0.971$, $p=0.001)$; and pyrene with 1OHPy at TMC $(r=0.878, p=0.002)$ and VNH $(r=0.745, p=0.005)$. Yamano et al. [63] and Rossbach et al. [70] also reported moderate to strong correlations between urinary metabolite concentration and personal exposure to the respective PAH.

Globally these results suggest that airborne PAHs at fire stations may contribute to firefighters' total PAHs body burden; the influence is more evident in firefighters exposed to the highest levels. Still the existence of other significant common sources (food, home air and/or outdoor air) cannot be discarded. Naphthalene and acenaphthene are the more volatile compounds and most of their environmental levels enter in the human body mainly through air. Fluorene, phenanthrene and pyrene are absorbed through the respiratory tract but also by the gastrointestinal tracts, and by the skin.

\section{Conclusions}

This work characterized firefightersí exposure to PAHs during their work shift at eight Portuguese fire stations by personal exposure monitoring and biomonitoring. Overall, $\mathrm{PM}_{2.5}$-bound $\Sigma \mathrm{PAH}$ concentrations ranged from $46.4-428 \mathrm{ng} / \mathrm{m}^{3}$, with $2-3$ aromatic rings accounting with $63.9-95.7 \%$ of $\Sigma$ PAHs. PAHs with $4-5$ or more aromatic rings corresponded to $0.789-2.05 \%$ and $2.54-34.7 \%$ of $\Sigma$ PAHs, respectively. The obtained data highlighted the importance of site specificity and poor building construction/conservation, as well as inappropriate building layout on environmental PAH levels at the studied fire stations. Still, firefighter's personal exposure to PAHs at Portuguese fire stations was well below the existent occupational exposure limits.

In accordance with the airborne PAHs profile, urinary 1-hydroxynaphthalene and 1-hydroxyacenaphthene were the predominant metabolites (66-96\% $\Sigma \mathrm{OH}-\mathrm{PAHs})$. Thus, it is recommended that total body burden of PAHs should not be based exclusively on 10HPy biomonitoring, as it has been performed in the large majority of studies. In addition, the contribution of some selected airborne individual compounds and $\Sigma$ PAHs to respective individual and $\mathrm{SOH}-\mathrm{PAHs}$ excretion in the post-shift urine was estimated for the first time in firefighters. The attained significant positive correlations for firefighters from four fire stations indicated the influence of occupational exposure on metabolite levels. Results for a larger number of fire stations, participants and number of (air and urine) samples are needed to draw more meaningful and statistically more significant conclusions. Also, a more comprehensive monitoring that includes all possible sources (food, home and outdoor air, etc.) would be precious to give more quantitative support to the impact of occupational exposure on firefighter's total PAHs internal dose.

\section{Conflict of interest}

The authors declare that there are no conflicts of interest.

\section{Statement of novelty}

This work characterized firefighters' exposure to PAHs during their work shift at eight fire stations by personal monitoring (18 PAHs) and biomonitoring (six urinary metabolites). Only two studies were found regarding firefighters' environmental exposure to PAHs at fire stations, both performed in USA. No information exists concerning other countries. Moreover, no study was found that simultaneously assessed airborne PAH exposure levels at fire stations and urinary levels of one or more PAH metabolites. Also, contribution of personal airborne individual and total PAHs exposure to respective individual and total $\mathrm{OH}-\mathrm{PAHs}$ excretion in urine was explored for the first time in firefighters.

\section{Acknowledgments}

The authors are thankful for the cooperation of Escola Superior de Saúde from Instituto Politécnico de Bragança and to all firefighters involved in the study. This work was supported by European Union (FEDER funds through COMPETE) and National Funds (FCT) through projects UID/QUI/50006/2013 and UID/EQU/00511/2013-LEPABE, by the FCT/MEC with national funds and co-funded by FEDER in the scope of the <gn1>P2020</gn1> Partnership Agreement. Additional financial support was provided by FCT through fellowships SFRH/BD/80113/2011 and SFRH/BPD/65722/2009.

\section{Appendix A. Supplementary data}

Supplementary data associated with this article can be found, in the online version, at http://dx.doi.org/10.1016/j.jhazmat.2016.03. 012.

\section{References}

[1] IARC Monographs on the Evaluation of Carcinogenic Risks to Humans. Painting, firefighting and shiftwork, International Agency for Research on Cancer 98 (2010) Lyon, France.

[2] NIOSH Pocket Guide to Chemical Hazards. U.S. Department of Health and Human Services, Public Health Service, Centers for Disease Control and Prevention, National Institute for Occupational Safety and Health (2007) Cincinnati, Ohio.

[3] IARC Monographs on the Evaluation of the Carcinogenic Risks to Humans: Some non-heterocyclic polycyclic aromatic hydrocarbons and some related exposures. International Agency for Research 92 (2010) 1-853.

[4] IARC Monographs on the Evaluation of the Carcinogenic Risks to Humans: naphthalene. Vol. 82 (2002) Lyon, France: World Health Organization, International Agency for Research on Cancer.

[5] World Health Organization, State of the science of endocrine disrupting chemicals2012 United Nations Environment Programme and the World Health Organization (2013) Geneva.

[6] US Environmental Protection Agency, Guidelines for Carcinogen Risk Assessment, EPA/630/P-03/001F, US Environmental Protection Agency 2005 Washington, D.C., [2015-12-19]. Available from: <http://www.epa.gov/raf/publications/pdfs/CANCER_GUIDELINES_FINAL_325-05.pdf>. 
[7] S.S. Franco, A.C. Nardocci, W.M.R. Günther, PAH biomarkers for human health risk assessment: a review of the state-of-the-art, Caderno Saúde Pública 24 (2008) 569-580.

[8] IARC Monographs on the Evaluation of Carcinogenic Risks to Humans: Some traditional herbal medicines, some mycotoxins, naphthalene and styrene International Agency for Research on Cancer 822002 1-556.

[9] K.W. Okona-Mensah, J. Battershill, A. Boobis, R. Fielder, An approach to investigating the importance of high potency polycyclic aromatic hydrocarbons (PAHs) in the induction of lung cancer by air pollution, Food Chem. Toxicol. 43 (2005) 1103-1116.

[10] M. Oliveira, K. Slezakova, C. Delerue-Matos, M.C. Pereira, S. Morais, Exposure to polycyclic aromatic hydrocarbons and assessment of potential risks in preschool children, Environ. Sci. Pollut. R. 22 (2015) 13892-13902.

[11] K. Slezakova, D. Castro, C. Delerue-Matos, M.C. Alvim-Ferraz, S. Morais, M.C. Pereira, Impact of vehicular traffic emissions on particulate-bound PAHs: levels and associated health risks, Atmos. Res. 127 (2013) 141-147.

[12] K. Slezakova, J.C.M. Pires, D. Castro, M.C.M. Alvim-Ferraz, C. Delerue-Matos, S. Morais, M.C. Pereira, PAH air pollution at a Portuguese urban area: Carcinogenic risks and sources identification, Environ. Sci. Pollut. Res. 20 (2013) 3932-3945.

[13] J. Lewtas, Air pollution combustion emissions: characterization of causative agents and mechanisms associated with cancer, reproductive, and cardiovascular effects, Mutat. Res. 637 (2007) 95-133.

[14] D.M. Gaughan, C.A. Piacitelli, B.T. Chen, B.F. Law, M.A. Virji, N.T. Edwards, et al., Exposures and cross-shift lung function declines in wildland firefighters, J. Occup. Environ. Hyg. 11 (2014) 591-603.

[15] D.M. Gaughan, P.D. Siegel, M.D. Hughes, C.-Y. Chang, B.F. Law, C.R. Campbell, et al., Arterial stiffness, oxidative stress, and smoke exposure in wildland firefighters, Am. J. Ind. Med. 57 (2014) 748-756.

[16] E.S. Soteriades, D.L. Smith, A.J. Tsismenakis, D.M. Baur, S.N. Kales, Cardiovascular disease in US firefighters-a systematic review, Cardiol. Rev. 19 (4) (2011) 202-215

[17] T.F. Booze, T.E. Reinhardt, S.J. Quiring, R.D. Ottmar, A screening-level assessment of the health risks of chronic smoke exposure for wildland firefighters, J. Occup. Environ. Hyg. 1 (2004) 296-305.

[18] K.W. Fent, J. Eisenberg, D. Evans, D. Sammons, S. Robertson, C. Striley, et al. Evaluation of dermal exposure to polycyclic aromatic hydrocarbons in fire fighters, Health Hazard Evaluation Report No 2010-0156-3196, United States Department of Health and Human Services, Centers for Disease Control and Prevention (2013) National Institute for Occupational Safety and Health. (2013).

[19] K.W. Fent, J. Eisenberg, J. Snawder, D. Sammons, J.D. Pleil, M.A. Stiegel, et al., Systemic exposure to PAHs and benzene in firefighters suppressing controlled structure fires, Ann. Occup. Hyg. 58 (7) (2014) 830-845.

[20] K.M. Kirk, M.B. Logan, Firefighting instructors' exposures to polycyclic aromatic hydrocarbons during live fire training scenarios, J. Occup. Environ. Hyg. 12 (2015) 227-234.

[21] B. Wei, K.U. Alwis, Z. Li, L. Wang, L. Valentin-Blasini, C.S. Sosnoff, Y. Xia, K.P. Conway, B.C. Blount, Urinary concentrations of PAH and VOC metabolites in marijuana users, Environ. Int. 88 (2016) 1-8.

[22] K.-H. Kim, S.A. Jahan, E. Kabir, R.J.C. Brown, A review of airborne polycyclic aromatic hydrocarbons (PAHs) and their human health effects, Environ. Int 60 (2013) 71-80.

[23] C.T. Baxter, J.D. Hoffman, M.J. Knipp, T. Reponen, E.N. Haynes, Exposure of firefighters to particulates and polycyclic aromatic hydrocarbons, J. Occup. Environ. Hyg. 11 (2014) D85-D91.

[24] D.M. Bolstad-Johnson, J.L. Burgess, C.D. Crutchfield, S. Storment, R. Gerkin, J.R Wilson, Characterization of firefighter exposures during fire overhaul, AIHAJ 61 (5) (2000) 636-641.

[25] K.W. Fent, D.E. Evans, Assessing the risk to firefighters from chemical vapors and gases during vehicle fire suppression, J. Environ. Monit. 13 (2011) 536-543.

[26] J.D. Pleil, M.A. Stiegel, K.W. Fent, Exploratory breath analysis for assessing toxic dermal exposures of firefighters during suppression of structural burns, J. Breath Res 8 (2014) 037107.

[27] M.S. Robinson, T.R. Anthony, S.R. Littau, P. Herckes, X. Nelson, G.S. Poplin, et al., Occupational PAH exposures during prescribed pile burns, Ann. Occup. Hyg. 52 (6) (2008) 497-508

[28] B.M. Alexander, C.T. Baxter, Plasticizer contamination of firefighter personal protective clothing -a potential factor in increased health risks in firefighters, J. Occup. Environ. Hyg. 11 (2014) D43-D48.

[29] T.Z. Fabian, J.L. Borgerson, P.D. Gandhi, C.T. Baxter, C.S. Ross, J.E. Lockey, et al., Characterization of firefighter smoke exposure, Fire Technol. 50 (2014) 993-1019.

[30] K.M. Kirk, M.B. Logan, Structural fire fighting ensembles: accumulation and off-gassing of combustion products, J. Occup. Environ. Hyg. 12 (2015) 376-383.

[31] J. Laitinen, M. Mäkelä, J. Mikkola, I. Huttu, Fire fighting trainers' exposure to carcinogenic agents in smoke diving simulators, Toxicol. Lett. 192 (2010) 61-65.

[32] B. Shen, T.P. Whitehead, S. McNeel, F.R. Brown, J. Dhaliwal, R. Das, et al., High levels of polybrominated diphenyl ethers in vacuum cleaner dust from California Fire Stations, Environ. Sci. Technol. 49 (2015) 4988-4994.

[33] F.J. Jongeneelen, Benchmark guideline for urinary 1- hydroxypyrene as biomarker of occupational exposure to polycyclic aromatic hydrocarbons, Ann. Occup. Hyg. 45 (2001) 3-13.
[34] F.J. Jongeneelen, A guidance value of 1-hydroxypyrene in urine in view of acceptable occupational exposure to polycyclic aromatic hydrocarbons, Toxicol. Lett. 231 (2014) 239-248.

[35] F. Gomes, M. Oliveira, M.J. Ramalhosa, C. Delerue-Matos, S. Morais, Polycyclic aromatic hydrocarbons in commercial squids from different geographical origins: Levels and risks for human consumption, Food Chem. Toxicol. 59 (2013) 46-54.

[36] M. Oliveira, K. Slezakova, C. Delerue-Matos, M.C. Pereira, S. Morais, Polycyclic aromatic hydrocarbons: levels and phase distributions in preschool environments, Indoor Air 25 (2015) 557-568

[37] Z. Li, L. Romanoff, S. Bartell, E.N. Pittman, D.A. Trinidad, M. McClean, et al., Excretion profiles and half-lives of ten urinary polycyclic aromatic hydrocarbon metabolites after dietary exposure, Chem. Res.Toxicol. 25 (2012) 1452-1461.

[38] C. Caux, C. O’Brien, C. Viau, Determination of firefighter exposure to polycyclic aromatic hydrocarbons and benzene during fire fighting using measurement of biological indicators, Applied Occupational and Environmental Hygiene 17 (5) (2002) 379-386.

[39] P. Edelman, J. Osterloh, J. Pirkle, S.P. Caudill, J. Grainger, R. Jones, et al., Biomonitoring of chemical exposure among New York City firefighters responding to the World Trade Center fire and collapse, Environ. Health Perspect. 111 (2003) 1906-1911.

[40] Directive of the European Parliament and of the Council relating to arsenic, cadmium, mercury, nickel and polycyclic aromatic hydrocarbons in ambient air Directive 2004/107/EC Off. J. Eur. Union., L23 2005 3-16.

[41] Joint Research Centre Technical Reports, Forest fires in Europe, Middle East and North Africa 2014 Joint report of JRC and Directorate-General Environment (2015) Luxembourg.

[42] Instituto da Conservação da Natureza e das Florestas, Provisonal Report of Forest Fires -2014, Departamento de Gestão de áreas Classificadas, Públicas e de Protecção Florestal 2014 Portugal.

[43] World Health Organization, World Health Survey B -Individual Questionnaire, World Health Organization Evidence and Information Policy. (2002) [2015-11-09] Available from: http://www.who.int/healthinfo/survey/whslongindividuala.pdf.

[44] K. Slezakova, D. Castro, C. Delerue-Matos, S. Morais, M.C. Pereira, Levels and risks of particulate-bound PAHs in indoor air influenced by tobacco smoke: A field measurement, Environ. Sci. Pollut. Res. 21 (2014) 4492-4501.

[45] D. Castro, K. Slezakova, M.T. Oliva-Teles, C. Delerue-Matos, M.C. Alvim-Ferraz, S. Morais, M.C. Pereira, Analysis of polycyclic aromatic hydrocarbons in atmospheric particulate samples by microwave-assisted extraction and liquid chromatography, J. Sep. Sci. 32 (2009) 501-510.

[46] D. Castro, K. Slezakova, C. Delerue-Matos, M. Alvim-Ferraz, S. Morais, M.C. Pereira, Polycyclic aromatic hydrocarbons in gas and particulate phases of indoor environment influenced by tobacco smoke: levels, phase distribution and health risks, Atmos. Environ. 45 (2011) 1799-1808.

[47] T. Chetiyanukornkul, A. Toriba, T. Kameda, N. Tang, K. Hayakawa, Simultaneous determination of urinary hydroxylated metabolites of naphthalene fluorene, phenanthrene and pyrene as multiple biomarkers of exposure to polycyclic aromatic hydrocarbons, Anal. Bioanal. Chem. 386 (2006) 712-718.

[48] J.N. Miller, J.C. Miller, Statistics for Analytical Chemistry, Pearson Education Ltd, Harlow. (2000).

[49] A.S. Kanagasabapathy, S. Kumari, Guidelines on standard operating procedures for clinical chemistry, World Health Organization, Regional Office for South-East Asia, New Delhi (2000) 25-28.

[50] R.W. Hornung, L.D. Reed, Estimation of average concentration in the presence of nondetectable values, Appl. Occup. Environ. Hyg. 5 (1990) 46-51.

[51] T.-C. Lin, F.-H. Chang, J.-H. Hsieh, H.-R. Chao, M.-R. Chao, Characteristics of polycyclic aromatic hydrocarbons and total suspended particulate in indoor and outdoor atmosphere of a Taiwanese temple, A, Journal of Hazardous Materials 5 (2002) 1-12.

[52] J. Perwak, M Byrne, S. Coons et al. An exposure and risk assessment for benzo[u]pyrene and other polycyclic aromatic hydrocarbons. Volume IV. Benzo[u]pyrene, acenaphthylene, benz[a]anthracene, benzo[b]fluoranthene, benzo[k]fluroanthene, benzo[g, h, i]perylene, chrysene, dibenz[u, h]anthracene, and indeno[1, 2, 3-c, a]pyrene(1982) Washington, D.C.: US Environmental Protection Agency, Office of Water Regulations and Standards. EPA 440/4-85-020-V4.

[53] K. Ravindra, R. Sokhi, R.V. Grieken, Atmospheric polycyclic aromatic hydrocarbons: source attribution, emission factors and regulation, Atmos. Environ. 42 (2008) 2895-2921.

[54] K. Slezakova, D. Castro, C. Delerue-Matos, M.C. Alvim-Ferraz, S. Morais, M.C Pereira, Impact of vehicular traffic emissions on particulate- bound PAHs: Levels and associated health risks, Atmos. Res. 127 (2013) 141-147.

[55] World Health Organization, Guidelines for indoor air quality: selected pollutants, World Health Organization Regional Office for Europe, 2010 Copenhagen, Denmark.

[56] M. Albuquerque, M. Coutinho, C. Borrego, Long-term monitoring and seasonal analysis of polycyclic aromatic hydrocarbons (PAHs) measured over a decade in the ambient air of Porto Portugal, Sci, Total Environ. 543 (2016) 439-448.

[57] World Health Organization, Biological Monitoring of Chemical exposure in Workplace-guidelines, World Health Organization 1996 Geneva.

[58] S. Brzeznicki, M. Jakubowski, B. Czerski, Elimination of 1-hydroxypyrene after human volunteer exposure to polycyclic aromatic hydrocarbons, Int. Arch. Occup. Environ. Health 70 (1997) 257-260. 
[59] F.J. Jongeneelen, F.E. Van Leeuwen, S. Oosterink, R.B. Anzion, L.F. van Der, R.P. Bos, H.G. van Veen, Ambient and biological monitoring of cokeoven workers: determinants of the internal dose of polycyclic aromatic hydrocarbons, $\mathrm{Br}$. J. Ind. Med. 47 (1990) 454-461.

[60] T.J. Buckley, P.J. Lioy, An examination of the time course from human dietary exposure to polycyclic aromatic hydrocarbons to urinary elimination of 1-hydroxypyrene, Br. J. Ind. Med. 49 (1992) 113-124.

[61] C. Viau, G. Carrier, A. Vyskocil, C. Dodd, Urinary excretion kinetics of 1-hydroxypyrene in volunteers exposed to pyrene by the oral and dermal route, Sci. Total Environ. 163 (1995) 179-186.

[62] J. Gündel, K.H. Schaller, J. Angerer, Occupational exposure to polycyclic aromatic hydrocarbons in a fireproof stone producing plant: biological monitoring of 1-hydroxypyrene, 1-2-3- and 4-hydroxyphenanthrene, 3-hydroxybenz(a) anthracene and 3-hydroxybenzo(a) pyrene, Int. Arch. Occup. Environ. Health 73 (2000) 270-274.

[63] Y. Yamano, K. Hara, M. Ichiba, T. Hanaoka, G. Pan, T. Nakadate, Urinary 1-hydroxypyrene as a comprehensive carcinogenic biomarker of exposure to polycyclic aromatic hydrocarbons: a cross-sectional study of coke oven workers in china, Int. Arch. Occup. Environ. Health 87 (2014) 705-713.

[64] C. Marie, M. Bouchard, R. Heredia-Ortiz, C. Viau, A. Maitre, A toxicokinetic study to elucidate 3-hydroxybenzo(a) pyrene atypical urinary excretion profile following intravenous injection of benzo(a) pyrene in rats, J. Appl. Toxicol. 30 (2010) 402-410.
[65] American Conference of Governmental Industrial Hygienists, Documentation for a Recommended BEI of Polycyclic Aromatic Hydrocarbons American Conference of Governmental Industrial Hygienists 2010 Cincinatti, Ohio, USA.

[66] D. Barbeau, S. Lutier, V. Bonneterre, R. Persoons, M. Marques, C. Herve, A Maitre, Occupational exposure to polyciclic aromatic hydrocarbons: relations between atmospheric mixtures, urinary metabolites and sampling times, Int. Arch. Occup. Environ. Health 88 (2015) 1119-1120.

[67] D. Barbeau, R. Persoons, M. Marques, C. Herve, G. Laffitte-Rigaud, A. Maitre, Relevance of urinary 3-hydroxybenzo(a) pyrene and 1-hydroxypyrene to assess exposure to carcinogenic polycyclic aromatic hydrocarbon mixtures in metallurgy workers, Ann. Occup. Hyg. 58 (2014) 579-590.

[68] C. Gendre, M. Lafontaine, Y. Morele, J.P. Payan, P. Simon, Relationship between urinary levels of 1-hydroxypyrene and 3-hydroxybenz[a]pyrene for workers exposed to polycyclic aromatic hydrocarbons, Polycyclic Aromat. Comp. 22 (2002) 761-769.

[69] K. Forster, R. Preuss, B. Rossbach, T. Bruning, J. Angerer, P. Simon, 3-Hydroxybenzo[a]pyrene in the urine of workers with occupational exposure to polycyclic aromatic hydrocarbons in different industries, Occup. Environ. Med. 65 (2008) 224-229.

[70] B. Rossbach, R. Preuss, S. Letzel, H. Drexler, J. Angerer, Biological monitoring of occupational exposure to polycyclic aromatic hydrocarbons (PAH) by determination of monohydroxylated metabolites of phenanthrene and pyrene in urine, Int. Arch. Occup. Environ. Health 81 (2007) 221-229. 